\title{
An assessment of counseling quality provided by community pharmacies to type 2 diabetic adult patients for oral therapy: a simulated patient study from Pakistan
}

\author{
Muhammad Majid Aziz'1),2),3),4), Shimin Yang ${ }^{1), 2), 3), 4)}$, Imran Masood ${ }^{5)}$, Shan Zhu ${ }^{1), 2), 3), 4), ~}$ \\ Muhammad Ali Raza ${ }^{6}$, Wenjing Ji ${ }^{1), 2), 3), 4)}$, Naveed Anwar ${ }^{7}$, Amna Saeed ${ }^{8)}$ and Yu Fang ${ }^{1), 2), 3), 4)}$ \\ 1) Department of Pharmacy Administration and Clinical Pharmacy, School of Pharmacy, Xi'an Jiaotong University, Xi'an, P. R. China \\ 2) The Center for Drug Safety and Policy Research, Xi'an Jiaotong University, Xi'an, P. R. China \\ 3) Global Health Institute, Xi'an Jiaotong University, Xi'an, P. R. China \\ 4) Shaanxi Center for Health Reform and Development Research, Xi'an, P. R. China \\ ${ }^{5)}$ Department of Pharmacy, Faculty of Pharmacy and Alternative Medicine, Railway Road Campus, Islamia University, Bahawalpur, \\ Pakistan \\ 6) Faculty of Pharmacy, Bahauddin Zakariya University, Multan, Pakistan \\ 7) Department of Pharmacy, Quaid-i-Azam University, Islamabad, Pakistan \\ 8) Punjab University College of Pharmacy, University of the Punjab, Lahore, Pakistan
}

\begin{abstract}
This study was conducted to assess quality of counseling provided to type 2 diabetic patients. For this crosssectional study, a simulated patient method was applied in 562 selected community pharmacies of Punjab, Pakistan. A scenario for the metformin oral therapy was developed that illustrates direct counseling for adult diabetic patients. Counseling and communication skills were also assessed. Descriptive statistics and chi-square tests were used for analysis. Only $29.4 \%$ of simulated patients received medication counseling directly; $47.6 \%$ received it on request. About $32.8 \%$ of clients were referred to a physician without counseling. The most frequently provided information was dietary instruction (94.8\%) and dose of therapy $(84.5 \%)$. Only one quarter $(25.3 \%)$ of simulated patients were asked about disease duration and similar rate $(25.0 \%)$ was found for discussions of special warnings. The side effects, drug storage, drug-drug interactions and duration of therapy were ignored. Minimal information was provided about other medication during therapy $(0.2 \%)$ and effect of medicine withdrawal $(2.7 \%)$. About $59.5 \%$ simulated patients were instructed for compliance to medication. Counseling to type 2 diabetic patients in Pakistani community pharmacies is not very satisfactory. Pharmacies' staff have little focus on counseling. Professional training of staff could improve counseling and communication skills.
\end{abstract}

Key words: Counseling, Type 2 diabetic patients, Metformin, Community pharmacies, Pakistan

DIABETES MELLITUS (DM) is one of the most prevalent non-communicable diseases of the world [1, 2]. Globally, more than 422 million adults are suffering with DM [3]. Diabetic adults have two to three time high risks of co-morbidities than non-diabetic adults [4]. The prevalence of diabetes (26.3\%) in Pakistan is alarming [5]. About 36 million people over the age 20 have DM. Every fourth Pakistani is suffering from DM [6]. The prevalence in urban areas $(28.3 \%)$ is higher than rural areas (25.3\%) [5]. More males are suffered with DM

Submitted Oct. 12, 2018; Accepted Dec. 24, 2018 as EJ18-0429 Released online in J-STAGE as advance publication Feb. 5, 2019 Correspondence to: Yu Fang, Department of Pharmacy Administration and Clinical Pharmacy, Health Science Center, Xi' an Jiaotong University, 76 Yanta West Road, Xi'an 710061, People's Republic of China.

E-mail: yufang@mail.xjtu.edu.cn than females [1]. Its management is a major concern; Pakistan spends $12 \%$ of its healthcare budget to cure DM [2]. The non pharmacological therapy including lifestyle modifications, physical activity, smoking avoidance and proper nutrition along with drug therapy are important aspects for managing DM [7].

Patient counseling has been recognized as an effective tool for DM management and provides economic and clinical benefits to patients. The rational medication improves the therapeutic outcome [8]. Patient counseling enhances patients' aptitude for making decisions toward medication and disease management [9]. Several studies reveal the significant positive impact of counseling on disease management, therapeutic outcome and patients' quality of life [10-14]. Pharmacists have proven role to improve diabetes therapy and disease management [4, 15, 16]. In-addition, counseling services provided by 
pharmacist to diabetic patients (DPs) are cost-effective [4]. In developed and developing countries, community pharmacists are ideally located to provide effective counseling and assistance to DPs $[4,7,17,18]$.

In Pakistan $79 \%$ of healthcare is provided through private sector and $77 \%$ of healthcare budget is consumed for purchase of medicines $[19,20]$. About $80 \%$ of medicines are sold through 80,000 community pharmacies $[20,21]$. Like other developing countries, community pharmacies can be potential source of diabetes care [7, $17,21,22]$. But still, no evidence exists about the role of community pharmacies in pharmaceutical care of DM. To the best of our knowledge, there are no studies on the standard of medication counseling to DPs. Therefore, we evaluated how pharmacies in, Pakistan, provide medication counseling services. This baseline study will provide a frame of reference to inform and strengthen medication counseling services.

\section{Methods}

A simulated patient (SP) method was used in selected community pharmacies in Punjab, Pakistan. This method has been used to assess medication counseling in community pharmacies [23-25]. This cross-sectional study was performed between June 2016 and February 2017.

\section{Simulated patients}

Thirteen SPs were selected and trained. All SPs, aged 24-27 years were male. SPs were final year students of Pharm D. Each SP had a good command of the local languages. To ensure equal data quality across SPs, rater reliability was analyzed using the percentage agreement method. Every SP was advised to complete a feedback record form immediately after their visit to each pharmacy. The feedback record (Supplementary file 1) form was a partially modified version of that used in previous studies [23, 24].

\section{Validity and reliability}

Three experts from academia of administrative pharmacy and experienced community pharmacist validated scenario and feedback record form by item-objective congruence score method. The average score $>0.5$ were consider good for content validity [26]. Every expert have option to score " -1 " for "clearly not measure", " 0 " for "unclear content" and " 1 " for "clearly measure".

Before study data collection, a pilot study in 20 pharmacies was also performed. The reliability of the feedback record form and methodology also was assessed. The feedback record form was partially modified based on the pilot study results. The results obtained from pilot study were not included in the final results.

\section{Communication skills assessment}

Counseling communication skills were assessed by SPs, who rated them on a 5-point Likert scale: very poor (a score of 1), poor (2), moderate (3), good (4), and very $\operatorname{good}(5)$.

\section{Study setting}

Study sites were community pharmacies in Punjab, Pakistan. The area of the Punjab province is 205,344 square kilometers and is the most populous province. The population is estimated to be more than 91 million, or $56 \%$ of the total national population [19].

\section{Pharmacy selection}

A list of pharmacies was obtained from Department of Health [27]. After confirming each pharmacy's licensure, pharmacies were arranged geographically with a serial number. Pharmacies were systematically selected from the list by this serial number. A stratified sampling technique was used to select pharmacies. Nine strata were formed based the Punjab governmental administrative divisions. Each stratum was further divided into four substrata: divisional city, district city, tehsil city, and suburban and rural area. The availability of medicine during the pilot study was also considered when determining the sample size. The sample size of pharmacies was calculated by Raosoft for response distribution (60\%), confidence interval (95\%) and margin of error (4\%) for the total 22,319 pharmacies [28]. Finally, total 562 pharmacies were selected (Supplementary file 2). We tried to ensure a homogeneous and uniform presentation of pharmacies from all areas of Punjab province.

\section{Scenario}

SP visited the pharmacy with a prescription of Metformin $250 \mathrm{mg}$ for the treatment of his newly diagnosed diabetes. If the medicine was dispensed without counseling, SP requested advice. This scenario illustrated direct counseling for adult patients with type $2 \mathrm{DM}$.

\section{Ethical approval}

The study design and protocols were approved by an ethics review committee at the Health Science Center of Xi'an Jiaotong University (Ref \# MR102-15/Phar) and the Pharmacy Research Ethics Committee at The Islamia University of Bahawalpur, Pakistan (Ref \# 67-2015/ PREC). The confidentiality of outcomes was also maintained by the oath of all data collectors in view of research ethics. None of the data contained identifying information; pharmacies were assigned identification numbers that were used in the data analysis process. 
Table 1 Specification of pharmacies, staff and visits $(N=529)$

\begin{tabular}{|c|c|c|c|}
\hline Characteristics & Category & $n(\%)$ & $p$-value* \\
\hline \multirow{3}{*}{$\begin{array}{l}\text { Class of pharmacy } \\
\text { (Number of the sale counters reported by SPs) }\end{array}$} & 1 & $322(60.9)$ & \multirow[t]{3}{*}{0.536} \\
\hline & $2-5$ & $192(36.3)$ & \\
\hline & $>5$ & $15(2.8)$ & \\
\hline \multirow[t]{3}{*}{ Number of employees at the time of visit as reported by SPs } & $1-5$ & $351(66.3)$ & \multirow[t]{3}{*}{0.585} \\
\hline & $6-10$ & $176(33.3)$ & \\
\hline & $>10$ & $2(0.4)$ & \\
\hline \multirow[t]{2}{*}{ Gender of pharmacy retailers (contacted) } & Male & $529(100.0)$ & \\
\hline & Female & $0(0.0)$ & \\
\hline \multirow[t]{5}{*}{ Age of contacted retailer (years), estimated by SP } & $<25$ & $2(0.4)$ & \multirow[t]{5}{*}{0.026} \\
\hline & $25-35$ & $235(44.4)$ & \\
\hline & $36-45$ & $72(13.6)$ & \\
\hline & $46-55$ & $156(29.5)$ & \\
\hline & $>55$ & $64(12.1)$ & \\
\hline \multirow[t]{7}{*}{ Day of the visit } & Monday & $35(6.6)$ & \multirow[t]{7}{*}{0.390} \\
\hline & Tuesday & $69(13.0)$ & \\
\hline & Wednesday & $51(9.6)$ & \\
\hline & Thursday & $64(12.1)$ & \\
\hline & Friday & $34(6.4)$ & \\
\hline & Saturday & $136(25.7)$ & \\
\hline & Sunday & $140(26.5)$ & \\
\hline \multirow[t]{3}{*}{ Time of visit } & $8: 00-12: 00$ & $107(20.3)$ & \multirow[t]{3}{*}{0.256} \\
\hline & 12:00-14:00 & $4(0.7)$ & \\
\hline & 14:00-22:00 & $418(79.0)$ & \\
\hline \multirow[t]{3}{*}{ Number of waiting customers } & $0-5$ & $316(59.7)$ & \multirow[t]{3}{*}{0.276} \\
\hline & $6-10$ & $207(39.1)$ & \\
\hline & $>10$ & $6(1.2)$ & \\
\hline \multirow[t]{2}{*}{ Waiting time (mints) } & $1-5$ & $174(32.9)$ & \multirow[t]{2}{*}{0.059} \\
\hline & $>5$ & $355(67.1)$ & \\
\hline \multirow[t]{3}{*}{ Total time of conversation (talk about medication) (mints) } & $\leq 2$ & $349(66.0)$ & \multirow[t]{3}{*}{0.087} \\
\hline & $3-5$ & $173(32.7)$ & \\
\hline & $>5$ & $7(1.3)$ & \\
\hline \multirow[t]{3}{*}{ Privacy during conversation } & Full provided & $0(0.0)$ & \multirow[t]{3}{*}{0.241} \\
\hline & Semi provided & $7(1.3)$ & \\
\hline & Not provided & $522(98.7)$ & \\
\hline
\end{tabular}

$* p$-value $<0.05=$ significant

\section{Data analysis}

The Statistical Package for the Social Sciences (SPSS) version 18.0 was used for descriptive analysis of the data related to counseling. Frequencies and percentages were measured. Chi-square tests were used to determine the influence of different factors on provision of counseling. The $p$-values less than 0.05 were consider statically significant.

\section{Results}

A total of $529(94.3 \%)$ pharmacies responded to SPs. At $33(5.8 \%)$ pharmacies medicine was not available. Most (60.9\%) visited pharmacies had a single counter. All retailers were male and it was estimated that many (58.0\%) were aged 25-45 years. Most pharmacies (98.7\%) failed to provide privacy during counseling. Only age influences the provision of counseling ( $p$-value 0.026 ) as given in Table 1. 
Table 2 Response of selected pharmacies to request of medication $(N=529)$

\begin{tabular}{llrr}
\hline Response & & $n$ & $\%$ \\
\hline Counseling without demand & & 156 & 29.4 \\
\hline \multirow{3}{*}{ On demand counseling } & Provided & 252 & 47.6 \\
& Questioning and advised to contact a doctor & 34 & 6.4 \\
& Directly advised to contact a doctor & 87 & 16.4 \\
\hline
\end{tabular}

Table 3 Information acquired by staff from SPs $(N=442)$

\begin{tabular}{lrc}
\hline Questions asked & $n$ & $\%$ \\
\hline Duration of disease or therapy & 112 & 25.3 \\
\hline Whether had taken any medicine before & 87 & 19.6 \\
Why the medicine was prescribed & 120 & 27.1 \\
\hline Any co-morbidity or its treatment? & 176 & 17.2 \\
\hline Any allergy to medicine in history? & 47 & 10.6 \\
\hline Do you know how to take medicine? & 109 & 24.6 \\
\hline You want to ask anything else? & 51 & 11.5 \\
\hline
\end{tabular}

Table 4 Contents of medication counseling provided to SPs $(N=$ 408)

\begin{tabular}{lrr}
\hline Information provided & $n$ & $\%$ \\
\hline The name of the medicine discussed & 305 & 74.7 \\
\hline Drug storage & 0 & 0.0 \\
$\begin{array}{l}\text { How to take the medication } \\
\text { (e.g. with/before/after meal) }\end{array}$ & 253 & 62.0 \\
\hline Dose of therapy & 345 & 84.5 \\
\hline $\begin{array}{l}\text { Duration of therapy or refill of prescription } \\
\text { Possible side effects of therapy }\end{array}$ & 0 & 0.0 \\
\hline Possible drug-drug interaction & 0 & 0.0 \\
\hline Life style modification or dietary instruction & 387 & 94.8 \\
\hline $\begin{array}{l}\text { Any other special warnings or precautions/ } \\
\text { contraindications }\end{array}$ & 102 & 25.0 \\
\hline Non compliance to medication and its effect & 243 & 59.5 \\
\hline $\begin{array}{l}\text { Effect of medicine withdrawal } \\
\text { Other medication during this therapy }\end{array}$ & 11 & 0.7 \\
\hline Reinsured that client understand all instructions & 353 & 86.5 \\
\hline
\end{tabular}

Less than one-third (29.4\%) of pharmacies provided counseling to SPs without being asked and $47.6 \%$ provided on the request of patient (Table 2).

Only one quarter $(54.0 \%)$ the pharmacies asked about the duration of disease or therapy. Few pharmacies $(27.1 \%)$ described reason of medicine prescription (Table 3).

Most pharmacies $(84.5 \%)$ provided information related to dose of therapy, but no clients were counseled
Table 5 Communication skills of counseling person $(n=408)$

\begin{tabular}{lc}
\hline Skill used & (Mean + SD) \\
\hline Eye contact & $2.4 \pm 0.5$ \\
Attention to customer & $2.4 \pm 0.5$ \\
Engagement of customer & $2.2 \pm 0.3$ \\
Non-verbal expressions used & $1.2 \pm 0.2$ \\
Provided written information & $1.1 \pm 0.3$ \\
\hline
\end{tabular}

about the storage of medicine (Table 4).

The communication skills of the person providing counseling were determined by including only cases in which the staff both asked and answered questions. Attention to the customer and contacts with patients was the skill ranked most highly $(2.4 \pm 0.5)$ and the provision of written information was the skill ranked lowest (1.1 \pm 0.3 ) by the SPs (Table 5).

\section{Discussion}

This study shows that counseling provided to type 2 DPs at community pharmacies in Pakistan is not very satisfactory [29]. The provision of counseling remain consistent among the visited pharmacies. Most factors have no significant effect on the counseling services ( $p$ value >0.05). However; identical to a Swedish study, current research also indicates that age of staff member engaged in DPs' counseling have effect on counseling services ( $p$-value $<0.05$ ) [24]. Privacy was not provided in the majority of pharmacies. Previous studies indicate that provision of privacy during the counseling plays a fundamental role [30-32]. It fulfills the patient satisfaction and enhances the confidence of pharmacists [30, $32]$. Less than one-third $(29.4 \%)$ of pharmacies provided counseling to SPs without being asked but similar to a previous study from Saudi Arabia [33], the response rate increased noticeably. The studies show that counseling rate for prescribed therapies in community pharmacies varied from $8 \%$ to $100 \%$ [34]. In majority case time provided by drug seller to the patients was less than 2 mints as reported in previous studies [35, 36]. More time provided by pharmacist to patients for their medication counseling also increase the patient's satisfaction [36]. 
Some side effects like diarrhea, metallic taste of mouth, stomach upset, nausea, vomiting and weakness are associated with metformin therapy [37, 38]. But drug sellers did not tell the possible side effects. Moreover, Pakistan's Recommendations for Optimal Management of diabetes from Primary to Tertiary care level (PROMPT) recommended that mentioned side-effects of metformin can be reduced, if taken with food [38]. But in this study only $62 \%$ SPs got the information in this regard.

Its observed that mostly DPs withdraw therapy at the appearance of side-effects [39]. The discontinuation of therapy significantly increases metabolic deterioration in patients and the cost of diabetes management. The long term use of oral hypoglycemic medicine is very necessary $[40,41]$. But information sharing for medicine withdrawal and its effects are ignored by drug sellers of Pakistan. Similarly, the storage of medicine and duration of therapy or refill of prescription were also completely missed. The drug-drug interaction, co-morbidity and other medication during treatment are discussed by few pharmacy retailers. The rate of special warnings $(25 \%)$ for medication is lower than Swedish pharmacies (32\%) but name of the medicine $(74.7 \%)$ is more frequently mentioned as compared to this Swedish study (65.0\%). However, no significant difference is found in rate of discussion about purpose of therapy [24].

Non-adherence to medication by type 2 DPs of Pakistan is common [42]. But several studies proves that pharmacists' intervention can improve adherence to medication of type 2 DM [43, 44]. But current study shows that about $59.5 \%$ drug sellers highlighted the effect of non-compliance to medication. In this regard this study resembles to a previous study of Spain [45]. Major reasons behind the poor medication counseling can be absence of qualified person in pharmacies and drug selling by unqualified salesmen [29].

This study highlights a positive aspect of counseling that most SPs got information for dose of therapy and life style modification or dietary instruction. These non pharmacological interventions also have very important role in the wellbeing of DPs [7]. This study also shows that staff of pharmacies is not skilled in communication. As communication skills is very important component of medication counseling [46, 47]. Finally, this study demonstrates that staff of community pharmacies need further trainings to enhance their knowledge and communication skills.

\section{Conclusions}

The staff of community pharmacies in Pakistan have little focus on DPs counseling. Drug storage, route of drug administration, and side effects are not discussed during prescription handling. The precautions about therapy and effects of other medications are overlooked. Scientific knowledge and counseling skills of staff seems poor. The strategies should implement to develop community pharmacy service on modern scientific basis. In addition, the continuous training of staff would help to strengthen medication counseling services.

\section{Limitations}

The present study has some limitations. First, this study was conducted in selected pharmacies. Although we tried to select a range of pharmacies from different areas, different results may have been found by selecting other pharmacies in other areas. Second, although rater reliability was analyzed, use of the SP method may have produced bias or misperceptions in assessing retailer age, provision of privacy, conversation time, and communication skills. To overcome any potential bias, a score range was used to determine retailer age and conversation time and retailer communication skills were measured using a 5-point Likert scale. Similarly, a 3-point scale was used to determine privacy. Third, medicines were not available in some pharmacies, which may have influenced the results. Unavailability of medicine is a universal phenomenon. This factor can be eliminated by any method in any setting. Therefore, overall findings may vary on availability of medicines in all pharmacies. Fourth, the assessment of conversation time did not reflect the exact counseling time; the SPs were advised to estimate how long they had talked with staff about medication and disease. Finally, all the scenarios were performed by male SPs aged between 24-27 years, as males are more dominant in Pakistani society. However, it's probable that scenario performed by these SPs may have affected the results. The research outcome may varies with different age and gender of SPs.

\section{References}

1. Meo SA, Zia I, Bukhari IA, Arain SA (2016) Type 2 diabetes mellitus in Pakistan: current prevalence and future forecast. J Pak Med Assoc 66: 1637-1642.
2. Gillani AH, Aziz MM, Masood I, Saqib A, Yang C, et al. (2018) Direct and indirect cost of diabetes care among patients with type 2 diabetes in private clinics: a multicen- 
ter study in Punjab, Pakistan. Expert Rev Pharmacoecon Outcomes Res 18: 647-653.

3. WHO (2018) Global report on diabetes. World Health Organization. Available at http://apps.who.int/iris/bitstream/ handle/10665/204871/9789241565257_eng.pdf;jsessionid= FBBB468B3A69E8C4DC9D04BE315C10FB? sequence=1 (Access at 16 Aug, 2018).

4. Hughes JD, Wibowo Y, Sunderland B, Hoti K (2017) The role of the pharmacist in the management of type 2 diabetes: current insights and future directions. Integr Pharm Res Pract 6: 15-27.

5. Basit A, Fawwad A, Qureshi H, Shera AS (2018) Prevalence of diabetes, pre-diabetes and associated risk factors: second national diabetes survey of Pakistan (NDSP), 2016-2017. BMJ Open 8: 1-10.

6. Nation (2017) Every 4th' Pakistani suffering from diabetes. The Nation. 19 Aug, 2017 https://nation.com.pk/ 19-Aug-2017/every-4th-pakistani-suffering-from-diabetes (Access at 16 Aug, 2018).

7. Venkatesan R, Devi ASM, Parasuraman S, Sriram S (2012) Role of community pharmacists in improving knowledge and glycemic control of type 2 diabetes. Perspect Clin Res 3: 26-31.

8. Dalal MR, Robinson SB, Sullivan SD (2014) Real-world evaluation of the effects of counseling and education in diabetes management. Diabetes Spectr 27: 235-243.

9. Lewis RK, Lasack NL, Lambert BL, Connor SE (1997) Patient counseling - a focus on maintenance therapy. Am J Health Syst Pharm 54: 2084-2098.

10. Mazzuca SA, Moorman NH, Wheeler ML, Norton JA, Fineberg NS, et al. (1986) The diabetes education study: a controlled trial of the effects of diabetes education. Diabetes Care 9: 1-10.

11. Stam DM, Graham JP (1997) Important aspects of self management education in patients with diabetes. Pharm Pract Manag $Q$ 17: 12-25.

12. Malathy R, Narmadha M, Ramesh S, Alvin JM, Dinesh BN (2011) Effect of a diabetes counseling programme on knowledge, attitude and practice among diabetic patients in Erode district of South India. J Young Pharm 3: 65-72.

13. Adepu R, Raheed A, Nagavi BG (2007) Effect of patient counseling on quality of life in type-2 diabetes mellitus patients in two selected south Indian community pharmacies: a study. Indian J Pharm Sci 69: 519-524.

14. Murata GH, Shaha JH, Adam KD, Wendel CS, Bokhari $\mathrm{SU}$, et al. (2003) Factors affecting diabetes knowledge in type 2 diabetic veterans. Diabetologia 46: 1170-1178.

15. Smith M (2009) Pharmacists' role in improving diabetes medication management. J Diabetes Sci Technol 3: 175179.

16. Alaqeel S, Abanmy N, AlShaya H, Almeshari A (2018) Interventions for improving pharmacist-led patient counselling in the community setting: a systematic review. Syst $\operatorname{Rev} 7: 71$.

17. Erku DA, Belachew SA, Mekuria AB, Haile KT, Gebresillassie BM, et al. (2017) The role of community pharmacists in patient counseling and health education: a survey of their knowledge and level of involvement in relation to type 2 diabetes mellitus. Integr Pharm Res Pract 6: 137-143.

18. Mitchell B, Armour C, Lee M, Song YJ, Stewart K, et al. (2011) Diabetes medication assistance service: the pharmacist's role in supporting patient self-management of type 2 diabetes (T2DM) in Australia. Patient Educ Couns 83: 288-294.

19. Aziz MM, Masood I, Yousaf M, Saleem H, Ye D, et al. (2018) Pattern of medication selling and self-medication practices: a study from Punjab, Pakistan. PLoS One 13: e0194240.

20. Babar ZU, Jamshed S (2008) Social pharmacy strengthening clinical pharmacy: why pharmaceutical policy research is needed in Pakistan? Pharm World Sci 30: 617619.

21. Hussain A, Malik M, Toklu HZ (2013) A literature review: pharmaceutical care an evolving role at community pharmacies in Pakistan. Pharmacol Pharm 4: 425-430.

22. FIP (2012) FIP Global Pharmacy, Workforce Report 2012. Available at http://www.fip.org/files/members/library/FIP workforce_Report_2012.pdf (Accessed 16 Aug 2018).

23. Paravattil B, Kheir N, Yousif A (2017) Utilization of simulated patients to assess diabetes and asthma counseling practices among community pharmacists in Qatar. Int J Clin Pharm 39: 759-768.

24. Tully MP, Beckman-Gyllenstrand A, Bernsten CB (2011) Factors predicting poor counselling about prescription medicines in Swedish community pharmacies. Patient Educ Couns 83: 3-6.

25. Kimberlin CL, Jamison AN, Linden S, Winterstein AG (2003) Patient counseling practices in U.S. pharmacies: effects of having pharmacists hand the medication to the patient and state regulations on pharmacist counseling. $J$ Am Pharm Assoc (2003) 51: 527-534.

26. Turner RC, Carlson L (2003) Indexes of item-objective congruence for multidimensional items. Int $J$ Testing 3 : 163-171.

27. SHMED (2018) Specialized Healthcare \& Medical Education Department. Available at http://health.punjab.gov.pk/ (Accessed 16 August 2018).

28. Raosoft (2018) Raosoft Sample Size Calculator. Available at http://www.raosoft.com/samplesize.html (Accessed 16 August 2018).

29. Hussain A, Ibrahim MI (2011) Medication counselling and dispensing practices at community pharmacies: a comparative cross sectional study from Pakistan. Int $J$ Clin Pharm 33: 859-867.

30. Melton BL, Lai Z (2017) Review of community pharmacy services: what is being performed, and where are the opportunities for improvement? Integr Pharm Res Pract 6: 79-89.

31. Hattingh HL, Emmerton L, Tin PNC, Green C (2016) Utilization of community pharmacy space to enhance privacy: a qualitative study. Health Expect 19: 1098-1110.

32. Albekairy AM (2014) Pharmacists' perceived barriers to patient counseling. J Appl Pharm Sci 4: 70-73. 
33. Alaqeel S, Abanmy NO (2015) Counseling practices in community pharmacies in Riyadh, Saudi Arabia: a crosssectional study. BMC Health Serv Res 15: 557.

34. Puspitasari HP, Aslani P, Krass I (2009) A review of counseling practices on prescription medicines in community pharmacies. Res Social Adm Pharm 5: 197-210.

35. Alfadl AA, Alrasheedy AA, Alhassun MS (2018) Evaluation of medication counseling practice at community pharmacies in Qassim region, Saudi Arabia. Saudi pharm J 26: 258-262.

36. Yang S, Kim D, Choi HJ, Chang MJ (2016) A comparison of patients' and pharmacists' satisfaction with medication counseling provided by community pharmacies: a crosssectional survey. BMC Health Serv Res 16: 131.

37. Nasri H, Rafieian-Kopaei M (2014) Metformin: current knowledge. J Res Med Sci 19: 658-664.

38. Shera AS, Basit A, Team P (2017) Pakistan's recommendations for optimal management of diabetes from primary to tertiary care level (PROMPT). Pak J Med Sci 33: 1279 1283.

39. Alhadramy MS (2016) Diabetes and oral therapies: a review of oral therapies for diabetes mellitus. $J$ Taibah University Medical Sciences 11: 317-329.

40. Nobels F, Van Gaal L, Rillaerts E, De Leeuw I (1989) Effect of oral antidiabetic drug withdrawal in type 2 diabetes. Diabet Med 6: 149-151.

41. Alleyne R (2010) Diabetes drug withdrawal will cause upheaval and extra cost. The Telegraph. 01 Nov, 2010.
Available at https://www.telegraph.co.uk/news/health/news/ 8100376/Diabetes-drug-withdrawal-will-cause-upheavaland-extra-cost.html (Accessed 16 Aug 2018).

42. Shams N, Amjad S, Kumar N, Ahmed W, Saleem F (2016) Drug non-adherence in type 2 diabetes mellitus; predictors and associations. J Ayub Med Coll Abbottabad 28: 302-307.

43. Antoine SL, Pieper D, Mathes T, Eikermann M (2014) Improving the adherence of type 2 diabetes mellitus patients with pharmacy care: a systematic review of randomized controlled trials. BMC Endocr Disord 14: 53.

44. Erku DA, Ayele AA, Mekuria AB, Belachew SA, Hailemeskel B, et al. (2017) The impact of pharmacist-led medication therapy management on medication adherence in patients with type 2 diabetes mellitus: a randomized controlled study. Pharm Pract (Granada) 15: 1026.

45. Barba EL, de Miguel MR, Hernández-Mijares A, AlonsoMoreno FJ, Orera Peña ML, et al. (2017) Medication adherence and persistence in type 2 diabetes mellitus: perspectives of patients, physicians and pharmacists on the Spanish health care system. Patient Prefer Adherence 11: 707-718.

46. Mesquita AR, Lyra DP Jr, Brito GC, Balisa-Rocha BJ, Aguiar PM, et al. (2010) Developing communication skills in pharmacy: a systematic review of the use of simulated patient methods. Patient Educ Couns 78: 143-148.

47. Perri M (2006) Communication skills for pharmacists. Am J Pharm Educ 70: 12. 